\title{
Terrestrial laser scanning for heritage conservation: the Cologne Cathedral documentation project
}

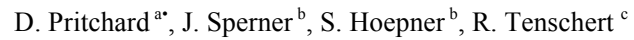 \\ ${ }^{a}$ EGIS, Heriot Watt University, Edinburgh, Scotland - dpritch5@jhu.edu \\ ${ }^{\mathrm{b}}$ Metropolitankapitel der Hohen Domkirche Köln, Dombauhütte, Köln 50667 Germany - \\ (joerg.sperner, sophie.hoepner)@dombau-koeln.de \\ c Otto-Friedrich-Universität Bamberg, Germany - ruth.tenschert@uni-bamberg.de
}

\section{Commission VI, WG VI/4}

KEY WORDS: Terrestrial laser scanning, 3D, heritage conservation, Gothic architecture, Cologne Cathedral

\begin{abstract}
:
Contemporary terrestrial laser scanners and photogrammetric imaging systems are an invaluable tool in providing objectively precise, as-built records of existing architectural, engineering and industrial sites. The comprehensive three-dimensional (3D) recording of culturally important sites such as heritage buildings, monuments, and sites can serve a variety of invaluable purposes; the data can assist in the conservation, management, and repair of a structure, as well as provide a visually engaging educational resource for both the public and scholars. The acquired data acts as a form of digital preservation, a timeless virtual representation of the as-built structure. The technical capability of these systems is particularly suited for the documentation of a richly articulated and detailed building such as the high Gothic Cologne Cathedral.
\end{abstract}

The 3D documentation of the Cologne Cathedral UNESCO World Heritage Site is a multiphase project developed by Heriot-Watt University, Edinburgh in partnership with the Fresenius University of Applied Sciences, Cologne, and the Metropolitankapitel der Hohen Domkirche Köln Dombauhütte. The project has also received generous support from Zoller + Fröhlich $(\mathrm{Z}+\mathrm{F})$ and the City of Cologne.

\section{INTRODUCTION}

This paper reflects on-going research in the applied use of terrestrial laser scanning (TLS) systems at architectural, heritage and urban sites to generate dimensionally verifiable point data to support the development of 2D CAD, 3D BIM, $3 \mathrm{D}$ animation and rendered imagery. The objective of the multi-phase project is to utilise TLS to precisely threedimensionally document and analyse the surface areas of the interior, exterior, twin towers, and adjacent precinct of the Cologne Cathedral UNESCO World Heritage Site. The large and richly ornamented Cathedral posed significant logistic challenges, one of the reasons why the building had yet to be comprehensively scanned.

At the creation of this paper, the Cathedral project is a work in progress, initially focusing on the data capture methodology. Further analysis of the 3D data is intended for applied conservation purposes as well as its use in the generation of $3 \mathrm{D}$ models for architectural interpretation and enhanced public engagement.

The documentation and development process during the Cologne project addressed similar challenges as experienced during the Scottish Ten Project (Lee, 2010), specifically the Mount Rushmore USA and Rani Ki Vav India projects, as well as the more recent work at Durham Cathedral and St. Michaels Mount, England (Davidson, 2015).

\section{THE COLOGNE CATHEDRAL PROJECT}

\subsection{Historic Challenges}

- Corresponding author.
Described as an 'exceptional work of human creative genius' (UNESCO 1995), the Cologne Cathedral was granted UNESCO World Heritage status in 1996. The iconic building is of tremendous emotive value to the citizens of the Cologne and the German nation; it is also considered one of the most significant architectural structures of European Christianity. The original design of the structure dates to 1164 and during a brief period, from 1880 until 1890, it was recognised as the tallest building in the world.

Throughout its long history, the Cathedral has endured numerous challenges and threats. Neglect, war, vandalism, urban growth, and environmental pollution have all had a significant impact on the physical fabric and structure of the building. A brief list includes the effects of the French Revolution, when the building was occupied by French troops and vandalized when used as a stable and prison. In 1811, architect Baurath Georg Möller surveyed the building and reported the walls of the choir had shifted, the wooden roof structures were rotten, the vaults cracked and rain water had penetrated the masonry joints (Jokilehto 1986).

The most destructive events were during World War Two. According to the Dombauhütte Archive, by the end of the war, "the building was seriously damaged by 14 major highexplosive bombs and over 70 firebombs, it was also hit by artillery and various projectiles. Most of the vaults in the main vessels of the nave and transept had collapsed, the organ and most of the nineteenth-century windows were destroyed, and there were countless instances of major and minor damage to the entire structure. The pier of the north tower had received a direct bomb hit, which posed a threat to the cathedral. The damage was repaired during the war using bricks as opposed to matching stone." (A brief history of Cologne Cathedral, 


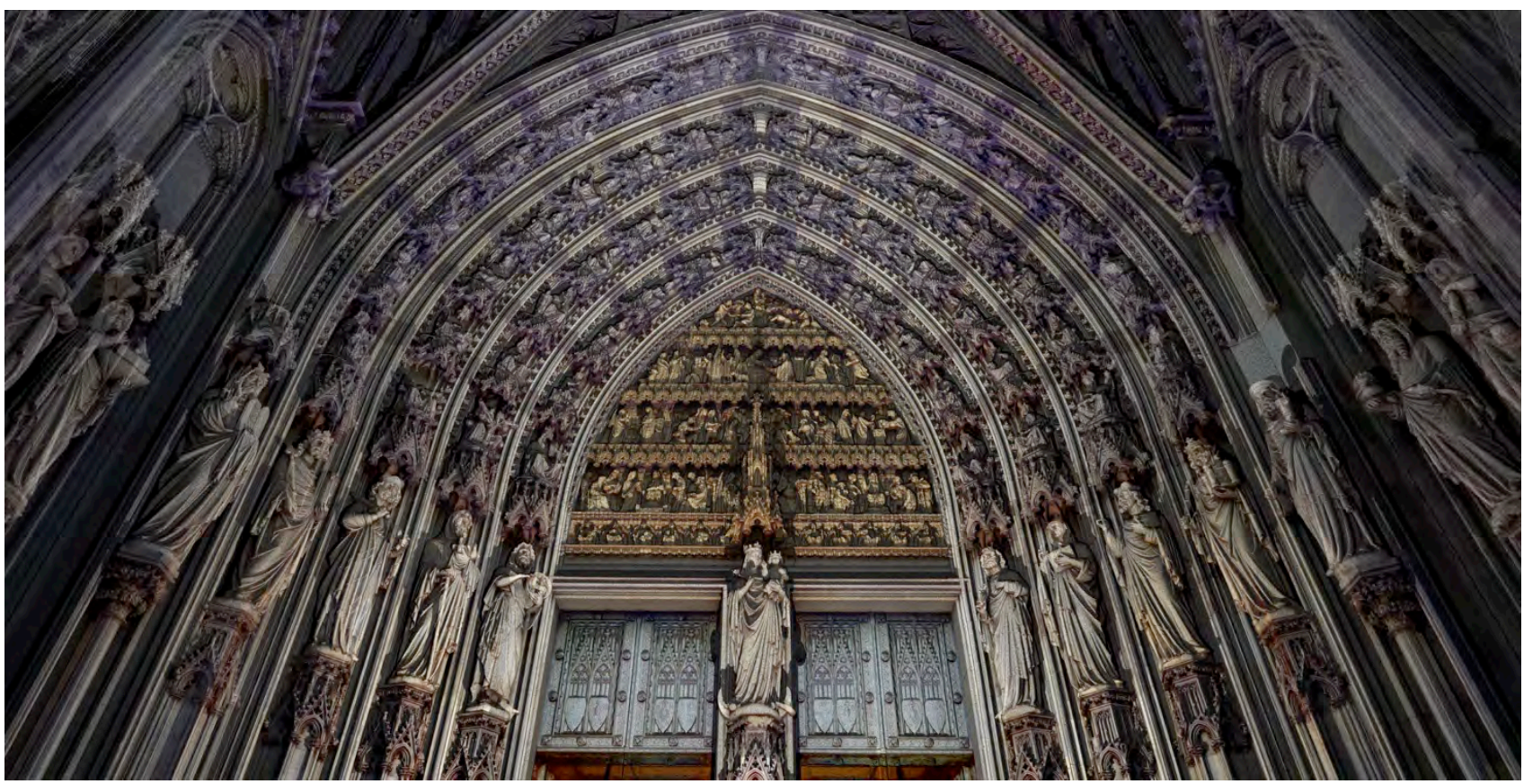

Image 1: Perspective point cloud rendering of main entry into the Cologne Cathedral. A combination of 15 terrestrial laser scans at varying heights with 360-degree HDR imagery.

2017). Despite the extensive repairs since the war, damage is still evident throughout many areas of the building.

Unfortunately, WW2 has an enduring legacy. In May 2015, 20,000 residents of Cologne were evacuated from the centre of the city when a 200-kilogram bomb was discovered near the Rhine River during construction work.

Contemporary conservation challenges are less-catastrophic but equally significant. They include the impact of adjacent engineering works, regional seismic activity, acid rain / air pollution accelerating stone surface decay, global warming, and vandalism. An ongoing concern is the pressure from the public and tourism; the Cathedral is an important pilgrimage and tourist site, with over 6 million visitors per year - as many visitors as at the Eiffel Tower in Paris. These numbers have a profound architectural impact in terms of accommodation (ticketing, security, engagement), humidity, dirt, surface wear, and vandalism. As an important pilgrimage site, the carbon emitted from the millions of votive candles being lit throughout the year.

In terms of architectural context, in 2004 the Cathedral was inscribed on the List of World Heritage in Danger because the UNESCO Committee believed that the "visual integrity" of the cathedral was endangered by proposed adjacent high-rise developments within the city.

Based on this background, a comprehensive TLS documentation of the Cologne Cathedral provided an objective $3 \mathrm{D}$ as-built record of the entire building, capturing its current physical condition including any previous surface damage, building settlement, and structural shifting. The data provides an invaluable dataset for future condition monitoring, conservation, and interpretation.

\subsection{Project Requirements}

Initiated as a research project with the Dombauhütte, the starting point of the documentation work was to demonstrate the effectiveness of contemporary TLS systems at a large heritage site. Given the prominence of the building, remarkably at the start of the project the Cathedral had never been completely laser scanned. As confidence in the project grew, the scope of the project was expanded to include the documentation of the entire World Heritage Site precinct, the building exterior (at various parapet levels), the roof areas and two towers. The project also included the main spaces within the building.

In discussion with the Dombauhütte, it was agreed that TLS systems would provide dimensional point data in a sufficient quality and resolution (Böhler 2003) for their conservation and maintenance purposes. Further justification for TLS included;

- The cathedral has been damaged, repaired and modified over the centuries and existing records may be inaccurate or under-detailed;

- A High Gothic cathedral is exceptionally ornate and difficult to document using traditional survey methods;

- Despite the Cathedral's relatively large size, due to the numerous parapets and ledges that surround the building, the distance between scanner and building surface is well within range of phase-based system;

- As recognised by UNESCO, the building has profound international significance and deserving of a comprehensive detailed archival record.

During the initial planning stage of the project the location of the scanners were based on the requirement to have the overall architectural form of the cathedral captured, but importantly, as much exterior and interior surface area coverage as possible. As an archival dataset, the adjacent architectural context such as the train station plaza and museum precinct was also included. The TLS position points were based on several factors such as ideal laser range, data resolution, data overlap, areas of occlusion, and visual obstruction. Specific challenges included the highly-articulated facade, the 


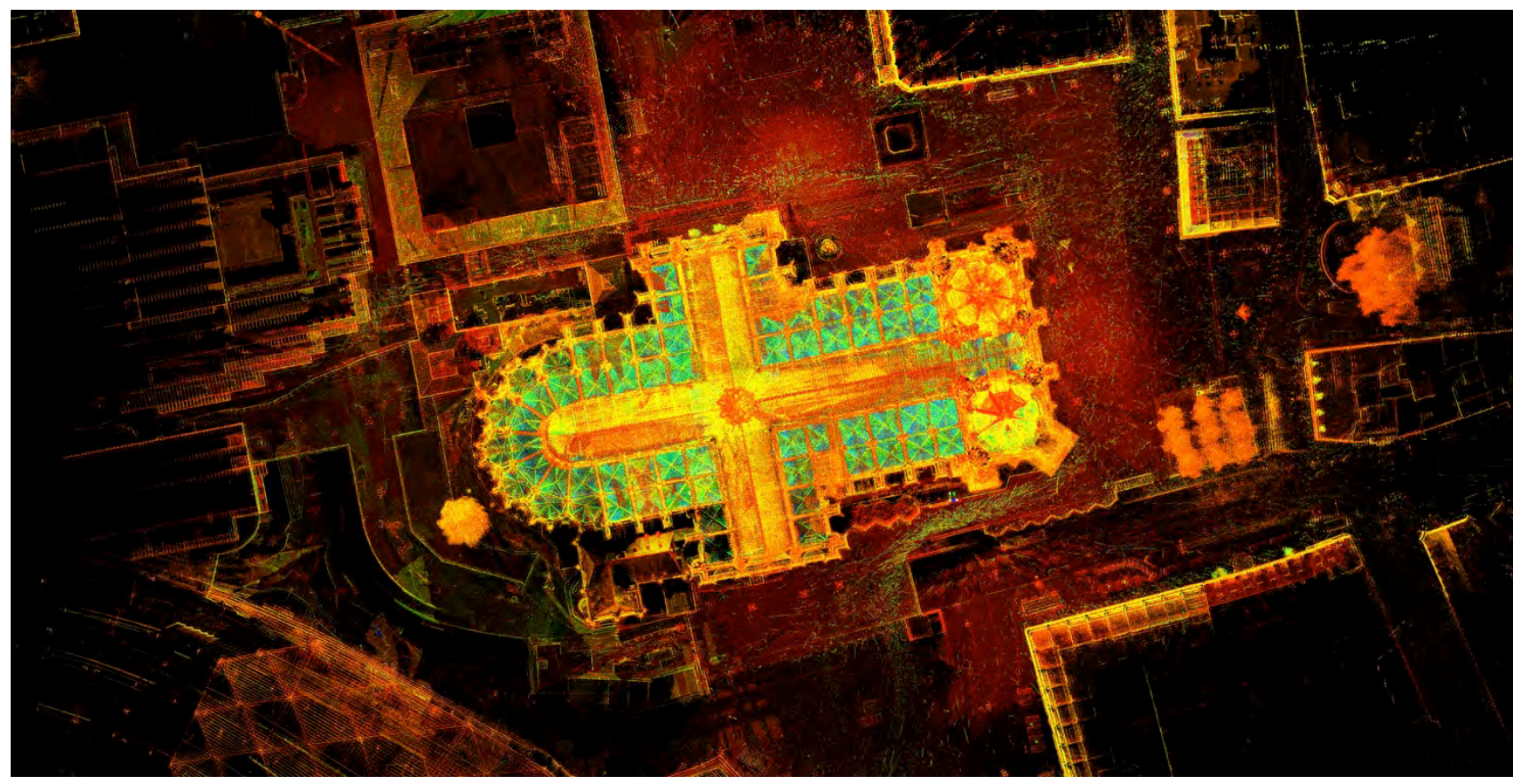

Image 6: Plan view rendering of the combined interior and exterior point data of the Cologne Cathedral precinct.

numerous flying buttresses and spires, the various parapet levels, and the height of the two towers.

\subsection{Documentation Systems}

The two scanning systems used in the project were the Zoller + Frohlich $(\mathrm{Z}+\mathrm{F})$ Imager $5010 \mathrm{C}$ and the Imager 5010X terrestrial laser scanners. Both systems were ideal systems for the Cathedral project due to their speed, range, data resolution, unit weight and the integrated High Definition Range (HDR) camera system.

The 5010C and 5010X are phase-based systems, utilising a Class 1 infrared laser, which is invisible, and rated as harmless, completely eye safe for both operator and public. A concern when scanning with heavy tourist activity at a World Heritage site. Relative to other contemporary scanning systems, the $5010 \mathrm{C}$ and $5010 \mathrm{X}$ have an exceptionally high and rapid data acquisition rate of 1.06 million points per second while maintaining a linearity error of more than $1 \mathrm{~mm}$ (within $20 \mathrm{~m}$ from surface). The systems have an approximate range of 187 meters and generate 360-degree point data based on a local coordinate system with intensity values.

On completion of the scanning sequence, the scanners initiate a series of 42 individual images, these are then combined to form a single 80-megapixel image. An important consideration in the documentation process is that the exact nodal point of the internal $5010 C$ and $5010 C X$ laser sensors and the onboard camera CCD sensor are at the same position. The result is that during the data post-processing, the imagery sits precisely onto the point data, providing photorealistic scan dataset. The automated data alignment avoids the tedious and time-consuming process of manual photography with hardware systems such as a panoramic head.

For most of the interior scanning a $Z+F$ SmartLight was attached to the $5010 \mathrm{C}$ to assist in the illumination of dark surfaces. The 1000 lumen light is specifically designed for the scanner's onboard camera with a neutral colour temperature with a maximum range of $10 \mathrm{~m}$. Although the $5010 \mathrm{C}$ has an
HDR camera and capable of balancing low and high light situations, a supplementary lighting system provided higher detailed colour imagery and helped compensate limited lighting conditions. The additional light was particularly useful when scanning the nine baroque 'Triumph of the Eucharist' tapestries suspended along the nave.

\subsection{Project Planning and Implementation}

One of the more compelling features of a Gothic cathedral is the explicit architectural order and continuity of structural features. The positioning of the laser scanners during the project was purposely based to work with this existing architectural order. For example, the scanner located at the centre of and interior bay between the columns, or at specific points between the buttresses or spires. The rationale was that these positions provided the best view for the scanner but given size and complexity of the building it required numerous scan set-up and at the same time resulted in considerable data overlap. The Z+F scanners were usually set at 3mm@10m point spacing with a high level of range noise reduction and full HDR imagery.

At the start of the project, existing Cathedral 2D CAD drawings were used to position the scan stations by drawing $50 \mathrm{~m}$ circles to determine set-up location and range. Working with the architectural order, the interior/exterior scans were proposed - using short distance scanning, multiple scan setups, inverting the scanner, positioning the laser scanner on an extension arm, and an extendable tripod.

The Cathedral has an existing network of brass control markers located throughout the building. The initial scans were set over the fixed points using the laser plummet and the heights recorded to provide further dimensional control. By using the control network, performing a subsequent partial or comprehensive laser scanning (e.g. in 5 to 10 years), incremental surface changes or movement can be identified.

Most the interior scanning was at ground level and along the $20 \mathrm{~m}$ level triforium walkway. Additional scanning occurred 


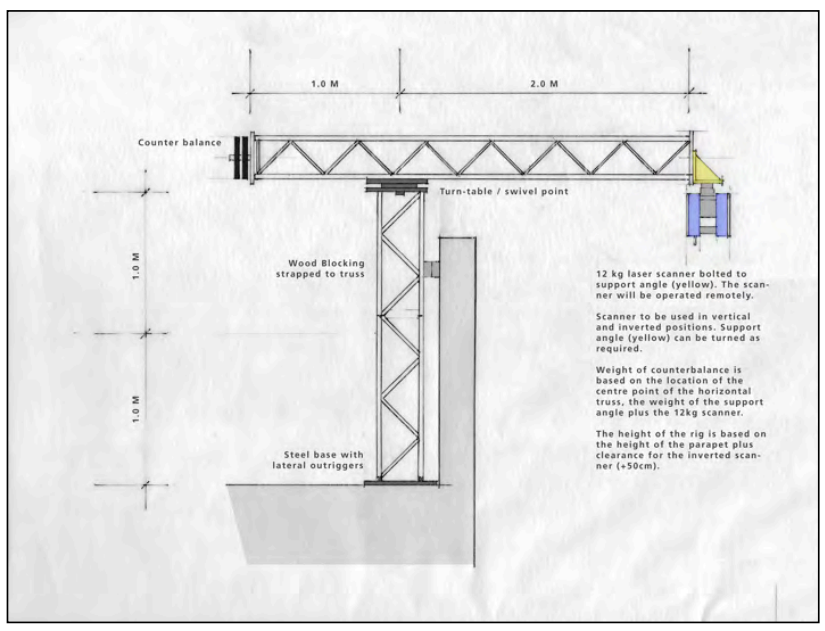

Image 2: Preliminary design sketch of the laser scanner extension rig.

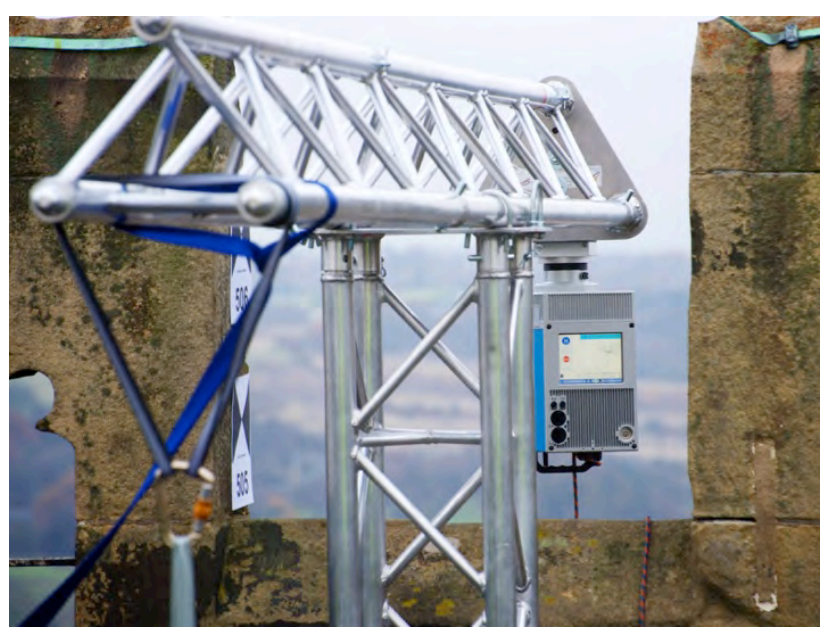

Image 3: Extension rig at Durham Cathedral, prior to the Cologne project.

along the interior walkways at the $27 \mathrm{~m}$ level of the north and south towers. In one situation, the 5010X was lowered through the ceiling keystone between the two towers using an inverted tripod (image 5). To connect the interior scan data with the other interior and exterior datasets, additional scanning was done at the main and south entries. Four additional direct connections were made at the north and south triforium levels, connecting the interior through the $20 \mathrm{~m}$ loft and then to the exterior.

Most of the interior scanning occurred during daylight hours, despite the numerous parishioners and visitors within the Cathedral, the interior laser scanning was thorough. Most of the interior surface areas of the nave, aisle, crossing, transept, choir and ambulatory were captured. The exterior scanning at ground had similar issues with commuters and tourists walking through the scanner's beam, but given that the people were mostly moving, the short distance between the scans, and the number of scans, the issue of scan data occlusion was reduced.

A significant challenge with acquired scan data was the number people being captured by the scanners onboard camera, especially at grade level. Without further image processing, the wrong colour information could be mapped onto the cathedral surfaces.

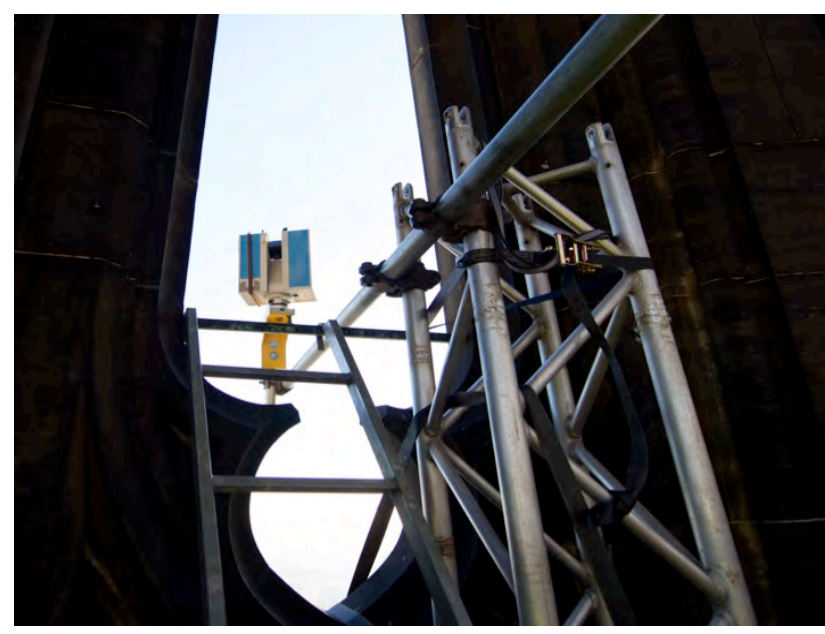

Image 4: Extension arm, North Tower Cologne Cathedral.

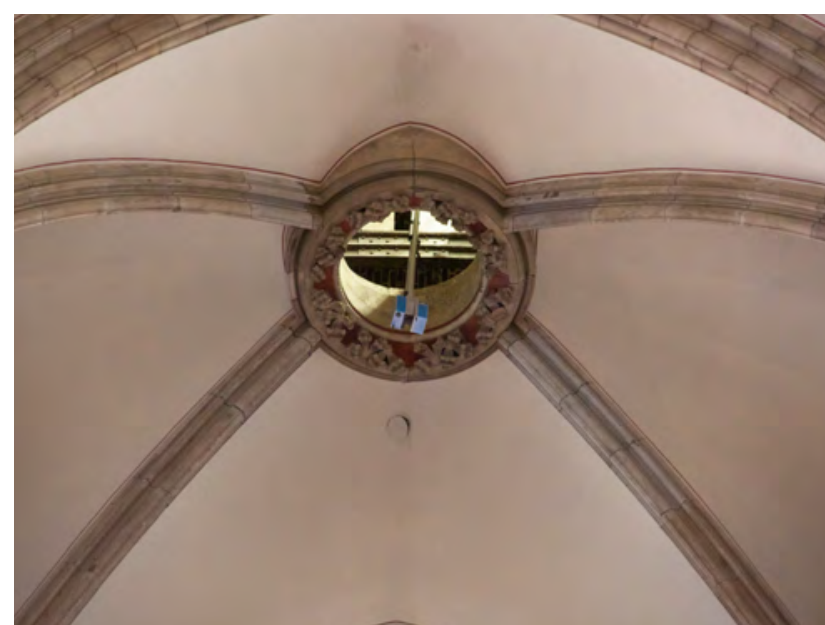

Image 5: The remotely operated, inverted 5010C TLS at the Cologne Cathedral.

The exterior scanning at ground encircled the entire Cathedral, with additional scans of adjacent buildings within the World Heritage Sector such as the Roman-Germanic Museum and the Dombauhütte Administration Building. Using the exterior geometry of the Cathedral, the scanners were positioned along the various parapet walkways and Crossing Tower.

The above-grade positioning of the scanner benefited from the wide parapets and accessible ledges, increasing the ability to acquire upper-level surface area, especially around the south, east, and north elevations. The TLS position points were also beneficial in that the angle of the laser was more direct to the surface as opposed to oblique when scanning from the ground (a significant issue when scanning such a large building).

Locating the scanner on grade and on the roofs of the adjacent buildings assisted in documenting the facades of the towers. Coverage of the two towers was supplemented by the horizontal and inverted scanning at the $150 \mathrm{~m}$ level.

As listed in Figure 1, at present there are 608 terrestrial scans, all with associated HDR imagery.

At the start of the project, it was determined that the data registration would be based on a software-based, cloud-tocloud system as opposed to the extensive use of survey targets. Although the lack of targets could reduce the speed of point 


\begin{tabular}{|c|c|c|c|}
\hline \multicolumn{2}{|c|}{$\begin{array}{l}\text { Interior Scan Locations / } \\
\text { Number of Scans }\end{array}$} & \multicolumn{2}{|c|}{$\begin{array}{l}\text { Exterior Scan Locations / } \\
\text { Number of Scans }\end{array}$} \\
\hline Grade Level & 84 & $\begin{array}{l}\text { Grade } \\
\text { Level }\end{array}$ & 68 \\
\hline $\begin{array}{l}20 \mathrm{~m} \\
\text { triforium }\end{array}$ & 26 & $\begin{array}{l}20 \mathrm{~m} \\
\text { Parapet } \\
\text { Walkway }\end{array}$ & 94 \\
\hline $\begin{array}{l}27 \mathrm{~m} \\
\text { towers }\end{array}$ & 5 & $\begin{array}{l}27 \mathrm{~m} \\
\text { Clerestory } \\
\text { Walkway }\end{array}$ & 77 \\
\hline $\begin{array}{l}45 \mathrm{~m} \\
\text { (inverted) }\end{array}$ & 4 & $\begin{array}{l}45 \mathrm{~m} \\
\text { Parapet } \\
\text { Walkway }\end{array}$ & 88 \\
\hline $\begin{array}{l}45 \mathrm{~m} \\
\text { workshop/I } \\
\text { oft }\end{array}$ & 37 & $\begin{array}{l}\text { Crossing } \\
\text { Tower }\end{array}$ & 8 \\
\hline $\begin{array}{l}\text { Bell / } \\
\text { Sculpture } \\
\text { Room }\end{array}$ & 10 & $\begin{array}{l}\text { North } \\
\text { Tower }\end{array}$ & 50 \\
\hline $\begin{array}{l}53 \mathrm{~m} \\
\text { catwalk }\end{array}$ & 11 & $\begin{array}{l}\text { South } \\
\text { Tower }\end{array}$ & 46 \\
\hline
\end{tabular}

Figure 1: Location and number of terrestrial scan stations, Cologne Cathedral.

cloud registration as well as affect the level of accuracy (especially if a Total Station was used to record the target positions), cloud-to-cloud was preferable as it enabled a quicker site setup, avoided the problem of affixing targets onto a large heritage structure, and having to address the problem of people obscuring or remove targets. A multitude of survey targets would also effect the visual quality of point data.

\subsection{Extension Rig}

As most TLS are a 'line-of-sight' systems, by securely extending the scanner horizontally outward, for example over an exterior parapet or from an upper-level gallery, the scanner can provide greater surface coverage and less occlusion. Having the ability to initiate both the high-resolution scanning and HDR imagery without additional hardware is exceptionally advantageous. The $5010 C / 5010 X$ can be extended out of reach of the operator via an extension arm and then remotely operated to capture a complete scan and imagery dataset.

This extension method was proven to be successful during a previous project at Durham Cathedral. By utilising a custombuilt aluminium extension rig the scanner captured highresolution surface data of the upper tower stonework. The position distance and angle of the scanner to the stone was shorter than scanning from a lower parapet and it provided a greater level of detail of the damaged stone and mortar. The configuration provided a unique view of the Cathedral roofs that were not seen by a typical tripod set-up, as well as captured other horizontal surface areas that are susceptible to direct weather and bird damage. In this situation, the 5010C was extended outward in an inverted position using an $8 \mathrm{~m}$ cantilevered truss and then operated via WiFi.

The Durham extension rig system required two technicians to assemble and operate. The system is made of commercialgrade theatre aluminum trussing components, with two outriggers for additional lateral stability. The assembled system is freestanding but for extra security and rigidity, a counterbalance and security tether were used. The total length of scanner arm is $3.0 \mathrm{~m}$, with the inverted scanner being able to extend outwards by $2.0 \mathrm{~m}$. The system takes 20 minutes to assemble and sits on a thick rubber pad to prevent any scratching of the floor.

The location of the scanner provided unique surface coverage of the central Durham Cathedral tower, specifically the upperlevel horizontal mortar joints and exterior surfaces that were most prone to weather and bird damage, as well as the roofs below. The rig system clearly captured the four main roofs of the cathedral, significantly reducing occlusion, aiding in the survey control, and specifically connecting the uppermost tower data with lower roof and ground datasets.

In certain situations, an unmanned autonomous vehicle (UAV) may be used to acquire exterior surface detail of a heritage site. At Durham and Cologne, an extension system was considered the better choice as the UAV would require shutting off wide areas to the public and there was a concern that the UAV could suffer a catastrophic failure and damage the building.

The Cologne tower documentation benefited from the experienced Cathedral scaffolding team who hauled and secured a metal truss within the inside the $150 \mathrm{~m}$ maintenance levels of the north and south towers. As indicated in Image 4, the $5010 \mathrm{C}$ was connected to a special bolted tribrach and custom-built metal angle. This was attached to a rigid pipe and then extended through the tower openings. The scanner was located $2.5 \mathrm{~m}$ from the exterior surface of the tower and had an unobstructed view of the building below. Like the Durham project, the scanner was remotely operated in a vertical position and then inverted. The scanner captured the opposing tower, both sides of the Cathedral roof (aiding in data registration) and the horizontal surfaces of the towers below the $150 \mathrm{~m}$ level.

\subsection{Data Processing and Point Cloud Registration}

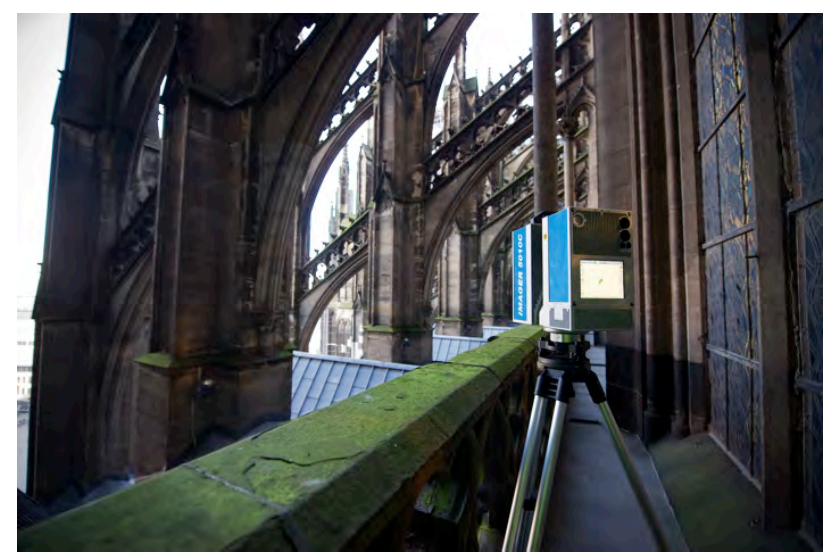

Image 7: Z+F 5010C terrestrial laser scanner, $27 \mathrm{~m}$ level, Cologne Cathedral. 


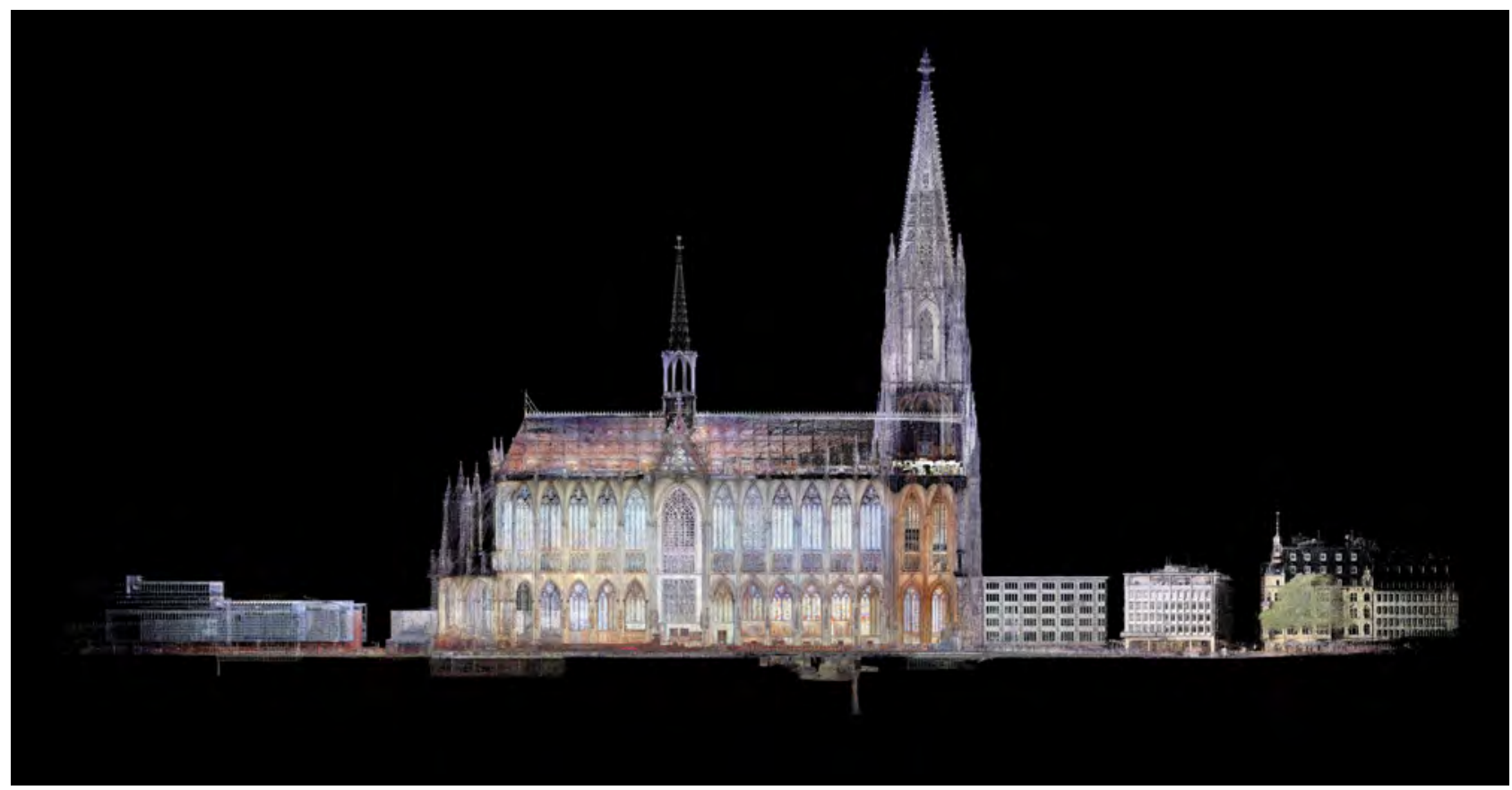

Image 8: Cross-section point cloud rendering through the Cathedral and precinct. Note the foundation tunnel at the base of the tower.

The onsite scanning at the Cathedral occurred over 4 campaigns during a 10 -month period. As each stage was completed, a copy of the data was transferred to a workstation for image development and preliminary data registration. The first stage of the process was to develop the associated colour information using the $Z+F$ LaserControl (v. 6.5) software. The software was used to create the individual .PNG images and then edited in Adobe Photoshop to address any image colour balance, saturation, or artefact issues, if necessary.

For production purposes, the data was organised per interior and exterior levels. Trial registrations were carried out using Leica Cyclone (v. 9.1) point cloud processing software using automatic and manual alignment. Due to the high number of scans the registrations were successful, as were the bridge/connection points between the interior and exterior datasets. The obvious challenge was to remove all the people and tourists from the grade level scan data. To avoid repetitive clean-up obvious artefacts and point cloud noise were removed in each scan via the Cyclone software.

\subsection{Post-Registration Data Development}

At present, large orthographic .TIFs and perspective renderings have been generated within Cyclone. To represent the highest quality output of the scan data, large tiled orthographic renderings of St. Peters Portal (the entry to the right of the main entry) were made.

Cross-sections through the exterior/interior Cathedral data have proved to be highly effective in visually explaining the spaces and structural systems within the building. Further high-resolution orthographic imagery is planned for each buttress.

A unique outcome of this project was that through connective scanning, a measurable line was generated from the lowest 'built' level of the Cathedral all the way to the top of the two towers. By registering the various scan datasets, a direct line can be made from the start of the South tower foundation to the upper most surface of the two towers (see image 8).
Individual sections of the registered dataset have been exported from Leica Cyclone as 'unified' .E57 format files into Autodesk ReCAP 360 (v. 3.1) for further data cleanup. Although there is an optimisation and reduction of the original data when importing into ReCAP, the ease of real-time navigation for data quality review and client presentation purposes has proven exceptionally beneficial. In addition, the ReCAP .RCP file can be quickly brought into other Autodesk applications such as AutoCad or Revit for further CAD development.

The interdisciplinary research project "Mittelalterliche Portale als Orte der Transformation" (University of Bamberg) funded by the German Federal Ministry of Education and Research is currently working with the dataset of the St. Peter's Portal. Based on the point clouds and the orthographic .TIFs precise as-built CAD-plans are drawn using Autodesk AutoCAD with Faro Pointsense Heritage. Like in previous parts of the project using point clouds as a base for the elevations, cross sections and floor plans on different levels helped tremendously to optimise the research workflow in terms of time-efficiency.

In addition, the level of detail given by the dataset ensures precise as-built plans, even concerning the laying pattern of the ashlars. These as-built plans are prepared for a one-week research campaign on-site and will be used for mappings showing information regarding surface deterioration, repairs, and replacement of stones, as well as for studies on the architectural structure and deformation. Based on the 3D information of the point cloud and detailed research on the site even exploded assembly drawings can be realised. The research results will contribute to a clearer understanding of how this unique medieval portal was erected and modified throughout the centuries.

The workflow of using orthographic images of the photorealistic point clouds can be adapted by the Dombauhütte Köln as a basis for site monitoring and for the planning of stone replacements. By using photorealistic and reflectance 
based images derived from the point cloud, the CAD results can be optimised.

\subsection{Future Data Development}

Future sub-millimetre scanning and digital photogrammetry of the entryway sculptures is proposed. This data will be able to reference the master scan dataset. The high resolution submillimetre structured light scanning $(0.2 \mathrm{~mm})$ will allow studies on surface deterioration, manufacturing techniques and a comparison between the original sculpture and the copy (see Beraldin 2004; Pavlidis 2007; and Pieraccini 2001) .

Further data processing work is planned for the individual Cathedral buttresses, specifically separating out each as an individual object and then generate orthographic-TIFs and 2D CAD. The meshing of the point data will use ThinkBox Sequoia software to generate 3D surface models. The plan is to provide a comparative dimensional study of each buttress.

A proposed use for the Cathedral scan and image data is to develop a dimensionally accurate 3D CAD model that would be used in the future planning of the World Heritage precinct. The urban dataset would be used for architectural design development, and specifically, being able to review the relationship between the new architecture and existing context and the Cathedral. TLS derived data has the advantage of providing the necessary information to develop a $3 \mathrm{D}$ urban model, therefore avoiding potentially troublesome intellectual property issues by mixing data owned by other organisations. (Pritchard 2007, Ceconello 2008).

\section{CONCLUSION}

This paper highlights the extensive use of TLS at the Cologne Cathedral UNESCO World Heritage Site to acquire a comprehensive, photorealistic 3D point cloud dataset of the interior and exterior of the building. The use of numerous short-range, multi-level scanner positions and extension rig scanning, proved to be an effective way to digitally document such a large and complex heritage structure. The Cathedral's immense size, height, and excessive human traffic were certainly challenging but the results of the project were successful and exceeded the original requirements of the Dombauhütte conservation team.

As a work in progress, further research will be carried out in the use of the data for conservation and monitoring purposes, initially with the St. Peter's portal and the choir buttresses. Longer term, the dataset will form the foundation for the development of an accurate 3D educational and engagement tool for better-informed urban design.

\section{ACKNOWLEDGEMENTS}

The authors would like to acknowledge the tremendous contribution and efforts of Zoller + Fröhlich, in particular Dr. Christoph Fröhlich, Christopher Held and Philipp Kresser, in the development of this project. Additionally, to recognise the initiative of Prof. Chris Wickenden and the great support from the staff and students of Hochschule Fresenius Köln. We would also like to show our gratitude to the technical staff at the Cologne Cathedral.

Douglas Pritchard has since left Heriot Watt University and is an Honorary Research Fellow at HATII, School of Humanities at the University of Glasgow and lecturer at the Krieger School of Arts and Sciences, Johns Hopkins University.

The Scottish Ten Project was developed at the Digital Design Studio at the Glasgow School of Art, Glasgow Scotland, the Durham Cathedral Project was commissioned by IIC Technologies and the Mount St. Michaels Project was commissioned by CyArk, Oakland USA.

\section{REFERENCES}

Abmayr T., Härtl F., Mettenleiter M., Heinz I., Hildebrand A., Neumann B., Fröhlich C. "Realistic 3D Reconstruction Combining Laserscan Data with RGB Colour Information", http://www.isprs.org/proceedings/XXXV/congress/comm5/p apers/549.pdf

Balzani, M., Pellegrinelli, A., Perfetti, N., Uccelli, F., "A terrestrial 3D laser scanner: Accuracy tests", Proc. 18th Int. Symp. CIPA 2001, pp. 445-453, 2001.

Beraldin, J.-A., Blais, F., Cournoyer, L., Godin, G., Rioux, M., Taylor, J., Active 3D sensing for heritage applications in Magistrat der Stadt Wien, Referat Kultur- elles Erbe, and Stattarcha ologie Wien. In: [Enter the Past]: The E-Way into the Four Dimensions of Cultural Heritage. BAR International Series, 1227. Archaeopress, Oxford, pp. 340-343 (2004).

Böhler, W. \& M. Bordas Vincent \& A. Marbs : Investigating Laser Scanner Accuracy. Proc. of the XIX. CIPA Int. Symposium, Antalya, Turkey, Sep. 30 - Oct. 4, 2003. International Archives for Photogrammetry and Remote Sensing (IAPRS). Vol. XXXIV - 5/C15, pp. 696-701 (2003).

Bork, R., "The Geometry of Creation: Architectural Drawing and the Dynamics of Gothic Design", Rutledge, New York, (2016).

Ceconello M., Paquet E., "Virtual Urban Design", 5th INTUITION International Conference, Turin Italy (2008).

Davidson, R., "Documentation at Saint Michael's Mount: Bringing Saint Michael's Mount into the 21st Century", http://www.cyark.org/news/documentation-at-saint-michaelsmount Oakland USA, (2015)

Jokilehto, J., "Part Three: Development of Conservation Theories, A History of Architectural Conservation" D. Phil Thesis, University of York, (1986).

Kacyra, B., Pritchard, D., Mitchell, D., "The Applied Use of Advanced Documentation Technologies in Heritage Conservation", ICOMOS Scientific Symposium - Malta, (2009).

Koller, D., Frischer, B., \& Humphreys, G., Research challenges for digital archives of 3D cultural heritage models, Journal on Computing and Cultural Heritage (JOCCH) Vol. 2 No. 3, December 2009, ACM New York, USA, Article No. 7, (2009).

Koelner-dom.de "A brief history of Cologne Cathedral." 20/04/17. https://www.koelner-dom.de/geschichte/a-briefhistory-of-cologne-cathedral/?L=1.

Lee, E., "Digitising the Legacy" American Surveyor, Vol. 7 No.7, (2010). 
Lerma, J.L., Navarro, S., Cabrelles, M. and Villaverde, V., 2010. Terrestrial laser scanning and close range photogrammetry for 3D archaeological documentation: the Upper Palaeolithic Cave of Parpallo' as a case study. Journal of Archaeological Science 37, pp. 499-507.

Mettenleiter, M.; Härtl, F.; Heinz, I.; Neumann, B.; Hildebrand, A.; Abmayr, T.; Fröhlich, C. "3D Laser Scanning for Engineering and Architectural Heritage", Zoller + Fröhlich (Z+F) GmbH, Simoniusstr. 22, D-88239 Wangen, Germany.

McGregor C, Mitchell D, Pritchard D, Rawlinson A, Wilson L, "3D Documentation of Global Historic Sites: The 'Scottish Ten' Project and its Applications for Cultural Heritage" in Proceedings of 3D-ARCH 2011 Conference, Trento, Italy. The International Archives of the Photogrammetry, Remote Sensing and Spatial Information Sciences, Vol. 38-5 (2011).

Pavlidis, G., Koutsoudis, A., Arnaoutologlou, F., Tsioukas, V., Chamzas, C., Methods for 3D digitization of cultural heritage. Journal of Cultural Heritage 8, 93-98 (2007).

Pritchard D., "Digital Documentation of the Built Environment: Construction of the Virtual City of Glasgow", CUPUM 2007, Iguassu Falls, Brazil (2007).

UNESCO World Heritage List, Cologne Cathedral No. 292 rev. August 1995

http://whc.unesco.org/en/list/292/documents/\%23ABevaluati on

Zacharias, D., Cologne Cathedral versus Skyscrapers - World Cultural Heritage Protection as Archetype of a Multilevel System, Max Planck UNYB 10, (2006). 